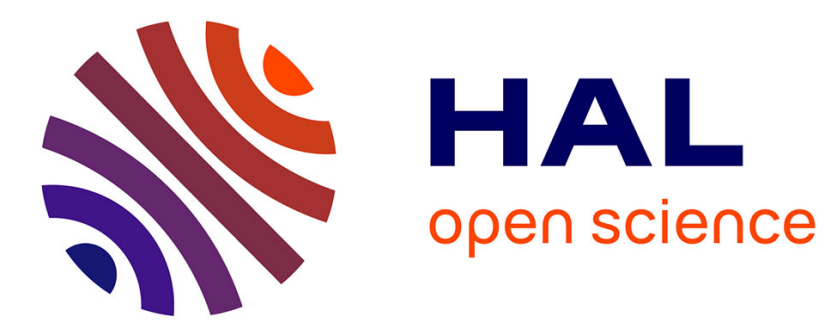

\title{
The impact of age and training on creativity: a design-theory approach to study fixation effects
}

Marine Agogué, Nicolas Poirel, Olivier Houde, Arlette Pineau, Mathieu

Cassotti

\section{- To cite this version:}

Marine Agogué, Nicolas Poirel, Olivier Houde, Arlette Pineau, Mathieu Cassotti. The impact of age and training on creativity: a design-theory approach to study fixation effects. Thinking Skills and Creativity, 2014, 11 (1), pp.33-41. hal-00825289

\section{HAL Id: hal-00825289}

https://hal-mines-paristech.archives-ouvertes.fr/hal-00825289

Submitted on 23 May 2013

HAL is a multi-disciplinary open access archive for the deposit and dissemination of scientific research documents, whether they are published or not. The documents may come from teaching and research institutions in France or abroad, or from public or private research centers.
L'archive ouverte pluridisciplinaire HAL, est destinée au dépôt et à la diffusion de documents scientifiques de niveau recherche, publiés ou non, émanant des établissements d'enseignement et de recherche français ou étrangers, des laboratoires publics ou privés. 


\title{
Understanding fixation effects in
}

\section{creativity: A design-theory approach}

\begin{abstract}
Despite the existence of many studies about the different aspects of fixation in creativity and design reasoning, the underlying mechanisms of fixation, i.e., the processes that interfere during creative reasoning and lead one to become fixated on a small number of unvaried solutions, remain unclear. In this paper, we propose a theoretical framework to model fixation based on $C-K$ design theory, which states that fixation is characterised as a set of restrictive heuristics activated in creative reasoning. We applied our framework in a set of experiments. We demonstrated how this framework makes sense of the varieties of fixation in design processes. We conclude by proposing three capabilities to understand fixation and overcome it: restrictive heuristics development, inhibitory control and expansion.
\end{abstract}

Keywords: fixation effects, design theory, design cognition

Today, there are great expectations for innovation and creativity. However, generating and developing new ideas is not as easy as it seems. The process of creating innovative ideas can become stale (Agogué, Le Masson \& Robinson 2012), as past investments (Arthur 1989; David 1985) and cognitive frames (Thrane et al. 2010; Kaplan \& Tripsas 2008) can lock creative efforts into a specific design path, preventing other possibilities from emerging. The idea of cognitive bias in innovation and creative settings agrees with what the literature on strategy has described (Prahalad \& Bettis, 1986) as a set of heuristic rules, norms and cognitive representations that guide paths of action while exploring new opportunities for development. More precisely, in the field of design, studies have highlighted how people are likely to face cognitive difficulties in creative situations. Jansson and Smith (1991) demonstrated that the solution explored first in a design task heavily influences the exploration of new solutions. This phenomenon is known as the fixation effect, i.e., "a blind, 
sometimes counterproductive, adherence to a limited set of ideas in the design process" (ibid.). If design literature builds on this notion of fixation in design processes (Purcell \& Gero, 1996; Chrysikou \& Weisberg, 2005; Perttula \& Liikanen, 2006; Linsey et al, 2010) or even proposes practical methodologies to overcome fixation effects (Van der Vlugt \& Wiering, 2002; Linsey et al. 2009; Hatchuel, Le Masson, \& Weil, 2011), the nature of the very mechanisms that lead people to remain fixed on certain ideas or solutions still needs to be explored. If other disciplines, such as cognitive psychology, are applied to the concept of the fixation effect, its modelling still remains vague, as fixation is mostly described as the spontaneous and unconscious activation of knowledge to find ways of solving a given design task (Smith et al, 1995).

Despite the range of diverse studies about the different aspects of fixation in creativity and design reasoning, the underlying mechanisms of fixation, i.e., the processes that interfere during creative reasoning and lead to one become fixated on a small number of unvaried solutions, are still unclear. Specifically, to model the fixation that occurs during design reasoning, one must more precisely understand the link between activated knowledge and the solutions that are consequently explored. This paper aims to examine the nature of fixation in creative contexts. We proposed a theoretical framework to model fixation based on $\mathrm{C}-\mathrm{K}$ design theory. $\mathrm{C}-\mathrm{K}$ theory models creative reasoning by separating two spaces, the knowledge space and the concept space, which takes into account the links between different knowledge bases and the possible design paths that can be explored using these pockets of knowledge. In this paper, we exposed a theoretical framework that allows us to characterise the nature of fixation mechanisms. We then used a creative task in which the aim was to design a way to drop a hen's egg from a height of 10 meters so that it does not break. We chose this task as it required minimal engineering expertise and allowed for many possible solutions. We applied our framework to this task to characterise the possible fixation effects, and we weighted this theoretical approach against a set of experiments in which 6 different populations (of various ages and levels of training) were given 10 minutes to generate as many solutions as possible to the creative 'egg task'. We demonstrated how different populations can be fixed in different ways and how our proposed theoretical framework made sense of the varieties of fixation in design processes. We concluded by proposing three 
capabilities that are required to understand and overcome fixation: restrictive heuristics development, inhibitory control and expansion.

\section{Fixation effect, a cognitive phenomenon in design}

Many factors can influence creative design processes. In their seminal paper about obstacles during creative reasoning, Jansson and Smith (1991) showed that the solution explored first in a design task heavily influences the exploration of new solutions. This phenomenon is called the fixation effect and is defined as a tacit, unconscious fixation on a limited scope of ideas during a creative design process. Their study stressed how individual designers can be trapped by an existing (or an obvious) solution, which constrains the generation of alternative solutions. The fixation effect is described as being due to the existence of precedents in design situations, generally in the form of visual representations. Design literature builds on the notion of fixation in design processes in various settings. Using a complementary perspective, Purcell and Gero (1996) also explored cognitive bias in design situations. They showed how fixation and conformity effects can occur in design processes when individuals have to design new objects to accomplish specific functions. They specifically studied the link between fixation and domain-specific knowledge. Furthermore, the nature of the stimuli can induce fixation in various ways, as the stimuli can be problem-relevant information given to participants (Tseng, Moss, Cagan \& Kotovsky, 2008), as well as non-verbal pictorial information (Cardoso, BadkeSchaub \& Luz, 2009). It has also been argued that fixation strongly relates to a sunk cost effect, i.e., the reluctance to change a path of action once significant resources have been invested in a specific path (Viswanathan \& Linsey, 2011). Moreover, several authors have proposed practical methodologies to overcome fixation effects, ranging from design methodologies (Hatchuel, Le Masson, \& Weil, 2011) to the use of analogies (Linsey et al. 2009; Smith, Linsey \& Kerne, 2010) or expansive examples (Agogué et al. 2011). For instance, Youmans (2010) argued that physical prototyping in design was a key element for avoiding fixation, as prototyping is argued to reduce the cognitive demands of a design process, hence easing editing processes that identify and eliminate 
fixation effects. In another study, Youmans also showed how brief interruptions during the design process help to reduce fixation (Youmans, 2011). This is known as the incubation effect and was also described by Dodds, Smith \& Ward (2002).

Nevertheless, to our knowledge, no model of fixation has been proposed, except in the work by Dong and Sarkar (2011) in which they built on the interpretation of fixation as an inappropriate interpretation of a given problem due to the difficulty of building a meta-representation. They proposed a mathematical model of fixation occurring at a meta-representation level. However, such a model accounts for fixation in problem-solving situations as a lack of flexibility in terms of representations (for example, the difficulty of using common objects in ways that are unexpected and novel) but does not rely on fixation in purely idea generation phases.

Disciplines other than design have examined the impact of cognitive bias on reasoning. Because fixation appears as a cognitive mechanism, it is not surprising that cognitive science has taken an interest in such an issue. Expanding to this discipline is all the more interesting, as bridging engineering design and cognitive psychology literature has proven its ability to describe the mechanisms that operate during creative design processes (Howard, Culley \& Dekoninck, 2008). In the field of cognitive psychology, scholars have clarified the obstacles that most people are likely to face in creative situations (Smith, Ward \& Finke, 1995; Abrahamm \& Windman, 2007; Kohn \& Smith, 2010). Scholars have shown how recently activated knowledge can constrain the ability to generate creative ideas. For example, creative problem solving can be inefficient when the solution requires subjects to generate an atypical object function and when the object's typical function has been primed (Duncker, 1945; Adamson, 1952). In psychology, this effect is labelled as functional fixedness. Other studies (Smith et al., 1995) have highlighted how the first ideas to be considered during creative idea generation can constrain the ideas that are subsequently generated. Furthermore, studies have shown how different populations can be affected in different ways by this fixedness. Deyfeter and German (2001) showed how young children are not affected by functional fixedness in the same way that older children are affected. In a different setting, Bonnardel and Marmèche (2004) underlined how experts can be more biased 
than novices in design situations, which is in agreement with studies about the impact of domain-related knowledge on creative idea generation (Wiley, 1998).

When integrating the different elements from existing work in engineering design and cognitive psychology, some questions arise when trying to more thoroughly understand fixation. These questions are as follows: what is the true nature of fixation? How can some activated knowledge constrain a design process? Can a model of fixation help to understand ways to unfix to overcome fixation?

\section{A design theory-driven theoretical framework to model fixation}

We propose to use a design theory approach to study fixation, as such theories aim to model creative reasoning, which offers a framework through which to study obstacles that can occur during such design process. We selected $\mathrm{C}-\mathrm{K}$ theory because it offers a modelling of creative reasoning by separating two spaces, the knowledge space and the concept space, which helps to account for the links between knowledge bases and the possible design paths that can be explored using these pockets of knowledge.

\subsection{Foundations of $C$ - $K$ theory}

C-K design theory (Hatchuel \& Weil, 2003; 2007; 2009; Le Masson, Weil \& Hatchuel, 2010) defines design reasoning as a logic of expansion processes, which organises the generation of objects that are unknown, thus leading to a truly novel design regime. It is named " $\mathrm{C}-\mathrm{K}$ theory" because its central proposition is a formal distinction between concepts and knowledge. $\mathrm{C}-\mathrm{K}$ theory models the generative process as an interaction between two expandable spaces, a space of concepts and a space of knowledge. Exploration in the knowledge space (K-space) encompasses the mapping of the knowledge base necessary for understanding and having a successful design path. A concept (located in the Cspace) is defined as a proposition without a logical status in the K-Space, i.e., an undecidable proposition, which means it is impossible to say if a concept is true 
or false. The C-space is a tree of undecidable propositions, and each node of the tree corresponds to a partition (in the mathematical sense) in several subconcepts of the mother concept. C-K theory models the creative process as the interrelated expansion of two spaces. In other words, the C-space is treestructured and describes the progressive and stepwise generation of alternatives, which are generally undecidable propositions before a conjunction can be interpreted as a solution. The K-space is formed by the network of memorised and activated knowledge that is used for the generative process of $\mathrm{C}$-space. Figure 1 summarises the basic features of C-K theory.

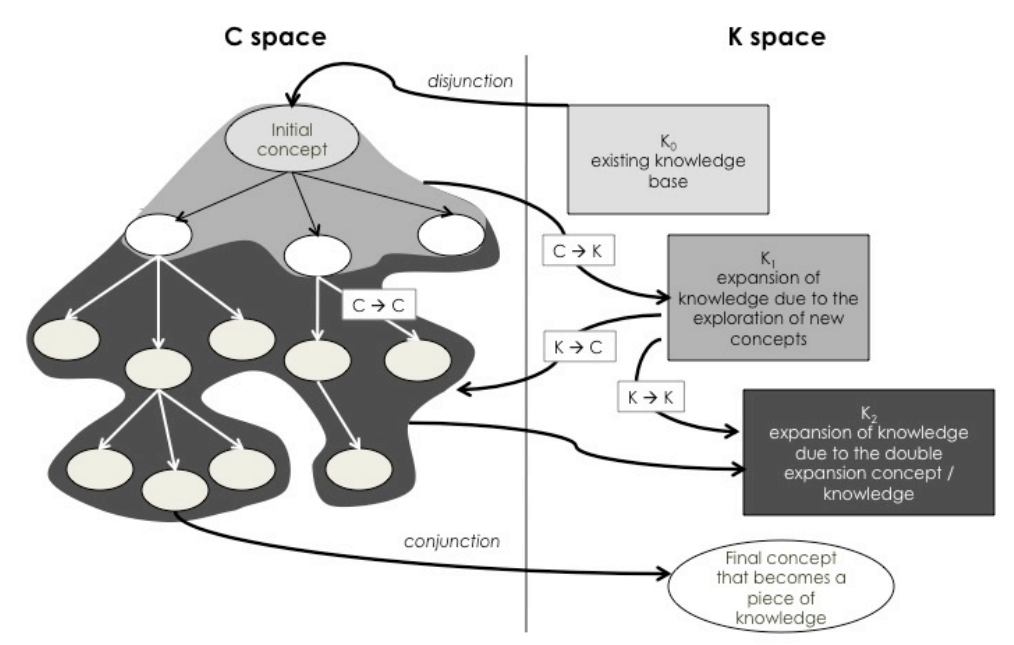

Figure 1: Features of $C-K$ theory: the expansion of two spaces

\subsection{Using $C$-K theory as a theoretical framework to model fixation effects}

$\mathrm{C}-\mathrm{K}$ theory establishes the framework of a design process based on refining and expanding the initial concept by adding attributes stemming from the knowledge space. The initial concept-set is thus partitioned step-by-step in several increasingly more refined sub-concepts. There are, however, two types of partitions (Hatchuel \& Weil, 2009; Hatchuel, Le Masson, \& Weil, 2011). The restrictive partition is a partition that restricts the space of possibilities without changing the definition or the attributes of the object to design. However, sticking to restrictive partitions does not allow for the redefinition of objects. 
Hence, an expansive partition is a partition that modifies the identity of the initial design object by adding unexpected attributes to that of the initial concept. It is precisely because of those expansions that novelty, including surprises, is possible.

Using the distinction between the restrictive partition and expansive partition, we propose the following model of a fixation effect: fixation is characterised as a set of restrictive heuristics activated in creative reasoning. We borrowed this notion of heuristics from cognitive psychology. A heuristic has to be understood as a set of simple, efficient rules that are learned or hard-coded by evolutionary processes, which allow for shortcuts to ease the cognitive load of reasoning. Thus, a restrictive heuristic is design reasoning that uses only spontaneously activated knowledge in the $\mathrm{K}$ space and restrictive partitions in the $\mathrm{C}$ space. Any expansion in the design reasoning, $\mathrm{K}$ space and/or $\mathrm{C}$ space leads to the exploration of solutions outside fixation, characterising expansive reasoning.

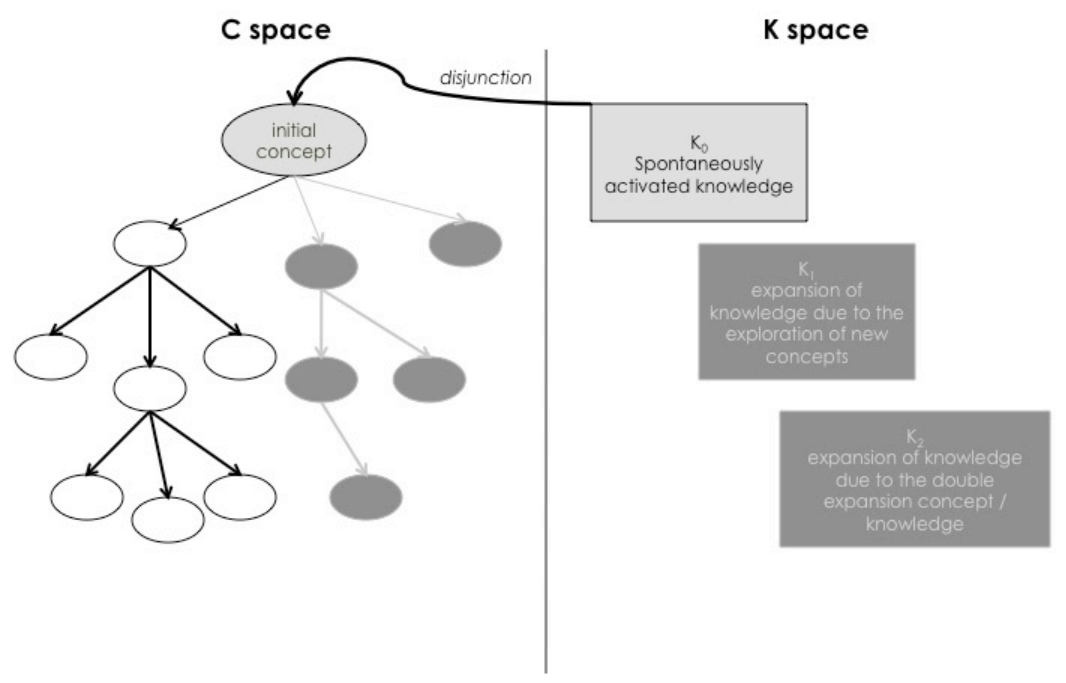

Figure 2: Model of a fixation effect as a set of restrictive heuristics: a spontaneously activated knowledge base (light grey) will determine partitions in the $C$ space (in white) and leads to the reduced exploration of possible solutions (the grey concepts will not be explored).

It may be noted that this model emphasises the distinction between mobilised knowledge (the knowledge that a designer has at his disposal) and activated knowledge (the knowledge that spontaneously comes to mind while thinking of a design problem). The effects of fixation are intrinsically linked to the activation of some specific knowledge in design reasoning. This activation then 
induces the exploration of a small number of conceptual paths, leaving the paths that require expansion unexplored.

\section{Experimenting on fixation effect}

We expanded this theoretical framework of the fixation effect and analysed it with a set of experiments where six different populations (with various ages and training) were given ten minutes to generate as many solutions as possible to the creative 'egg task'. In the first step, we used the proposed framework to explore possible paths of innovation, capturing the possible generation of new knowledge and objects about the matter of dropping an egg without breaking it. Thus, we characterised the emergence of restrictive heuristics, or in other words, the difficulty to expand in both $\mathrm{C}$ and $\mathrm{K}$ spaces. In the second step, we asked different populations to generate solutions to the egg task. After assessing the differences of fixation among the different populations, we showed how our theoretical framework made sense of this variety of fixation in the creative design process.

\subsection{Modelling a distribution of possible alternatives to a creative task}

To use C-K theory in our study, we first gathered the knowledge, expertise and solutions usually proposed for the creative 'egg task' (shells, mattresses, parachutes). Our hypothesis was that this knowledge basis is what is spontaneously activated while solving this task. We then expanded in the Cspace by showing the hidden partitions that had been made to achieve the design of devices that either changed the reception or the fall. The objective was to drop an egg from a 10-meter height without breaking it using a device that is inert (e.g., not living). The expansions, (a) without using a device and (b) using a living device, forced us to expand in the K-space and look for new knowledge (about egg properties, living devices etc.), which then allowed us to think of new expansions in the $\mathrm{C}$-space (such as using the natural properties of the egg or modifying them). This allowed us to map the possible solutions axis and to think 
of possible solution paths that do not spontaneously come to mind (for example, training an eagle to catch the egg, using the natural robustness of the longitudinal axis of an egg and freezing the egg). In contrast, the restrictive heuristics do not require an expansion of knowledge or a concept that characterises the fixation effect, as the restrictive heuristics demonstrate damping the shock, protecting the egg and slowing the fall. The restrictive heuristics and expansions are shown in Figure 3.

C space

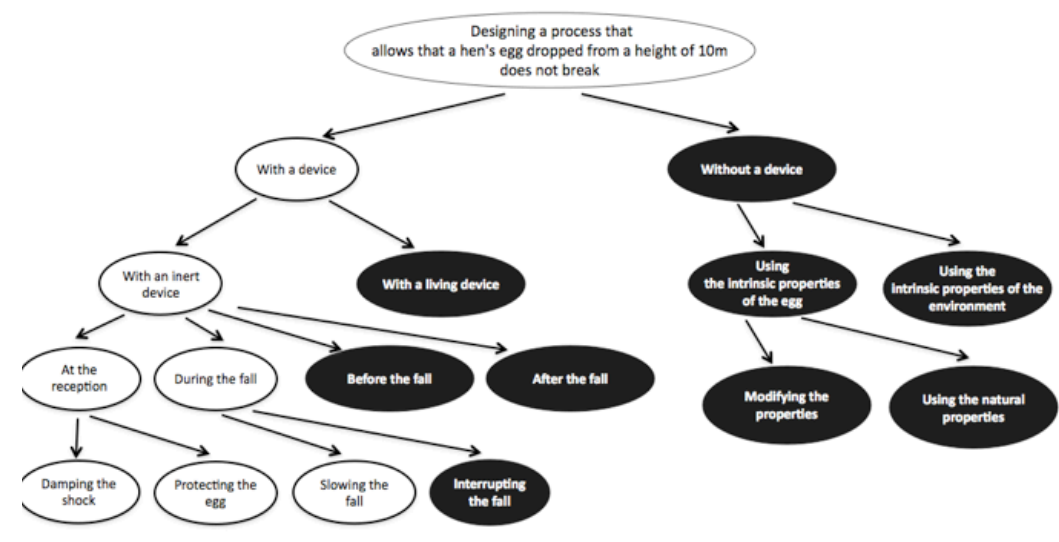

K space

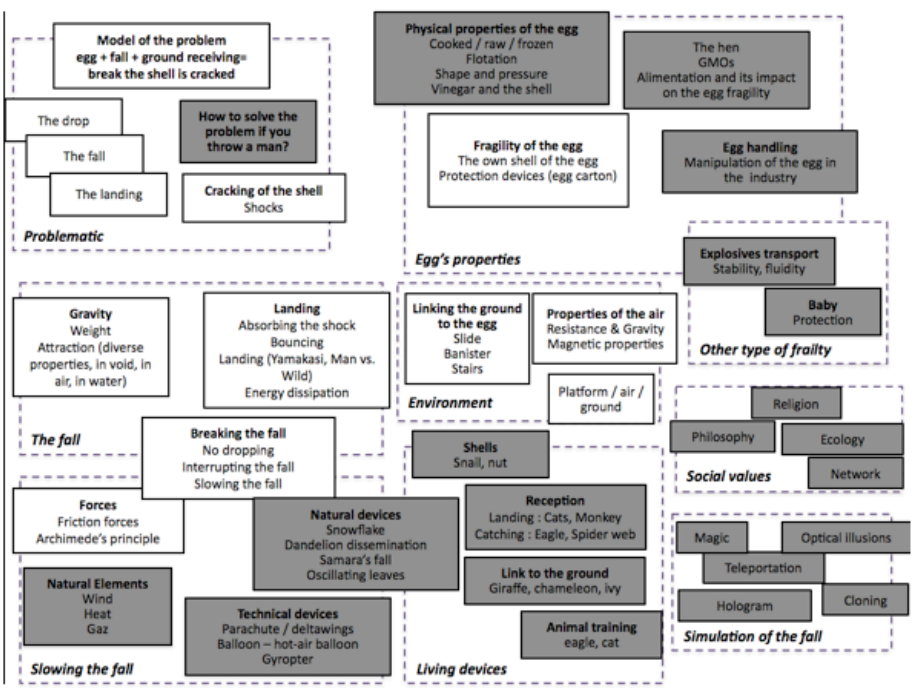

Figure 3: Modelling expansive and restrictive reasoning in the 'egg task'. The knowledge and concepts in white represent restrictive reasoning, the knowledge and concept in dark represent expansive reasoning. Three restrictive heuristics appear: damping the shock, protecting the egg and slowing the fall.

\subsection{Participants and Procedure}

The current investigation included 142 participants. The sample was divided into five groups based on age and training. The composition of the groups is described in table 1 . 
Table 1: Composition of the groups in the experiment

\begin{tabular}{|c|c|c|c|}
\hline Name of the group & N & Age (mean) & Training level \\
\hline Children & 18 & 10.1 & Elementary school \\
\hline Adolescents & 30 & 14.6 & High school \\
\hline Psychology students & 28 & 18.8 & Under-graduate \\
\hline Engineering students & 33 & 22.5 & Master students \\
\hline Entrepreneurs & 17 & 23.5 & Master students \\
\hline Designers & 16 & 23 & Master students \\
\hline
\end{tabular}

Each participant was given ten minutes to individually generate and silently write down as many original solutions as possible to the following problem: "Ensure that a hen's egg dropped from a height of 10 meters does not break."

\subsection{Results}

We used the categories of solutions deduced from the model of restrictive and expansive reasoning presented in figure 3 to analyse the distribution of answers. Every group appeared to be subject to a fixation effect, as the percentage of solutions on the three restrictive categories, "damping the shock", "protecting the egg" and "slowing the fall", were all between $63 \%$ and $81 \%$. Figure 4 presents the percentage of answers for each group and is focused on the three categories issued from restrictive heuristics. 


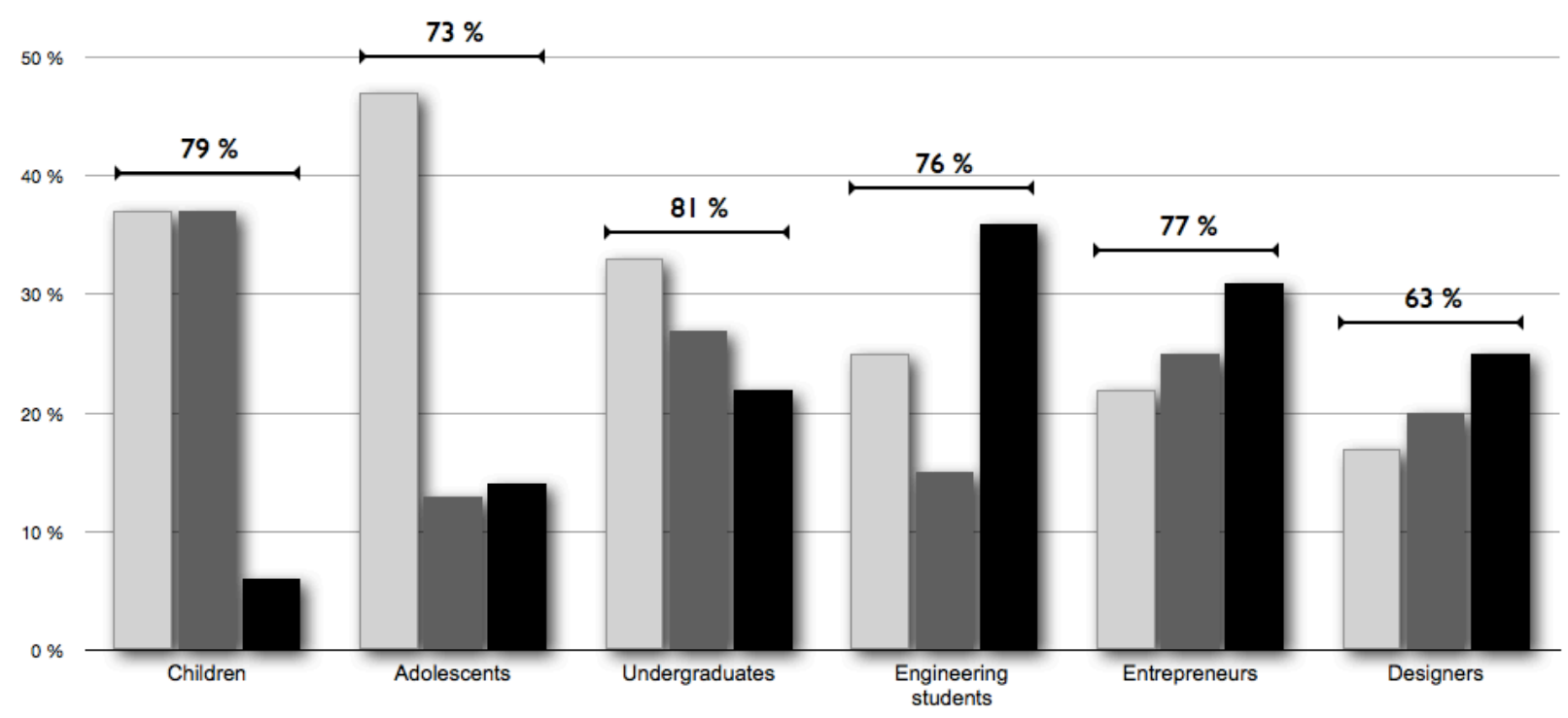

Figure 4: Results of the percentage of answers on each restrictive heuristic depending on the population. The percentages below the graph represent the total percentage of answers given within the three restrictive heuristics.

This graph shows the variety of fixation effects depending on the studied population. Group comparisons were performed using Fisher exact tests. Three main points emerged:

1. The evolution of fixation over age. Looking at the results of the first three categories, i.e., children (age 10), adolescents (age 15) and adults (psychology students, age 20), the nature of fixation evolved with age (see figure 5). Indeed, adults proposed a significantly smaller percentage of answers than adolescents in the category "damping the shock" ( $p<$ $.005)$. For the category "protecting the egg", adolescents proposed less answers than adults $(p<.005)$ and children $(p<.005)$. For "slowing the fall", adults proposed a higher percentage of solutions than children $(p<$ $.01)$ and adolescents $(p=.07)$. 

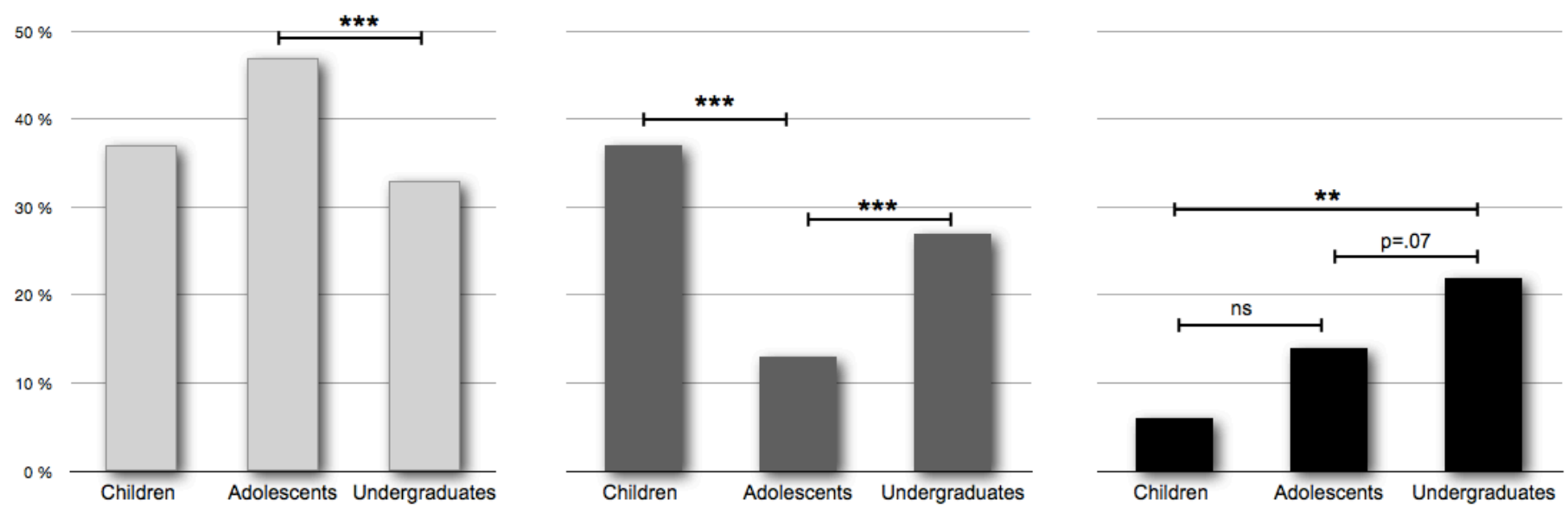

Figure 5: Evolution over age of the results of percentage of answers per restrictive category, using Fisher exact tests $(* p<.05 ; * * p<.01 ; * * * p<$ $.005)$

2. The different fixations between trainings. Looking at the last four population groups, our results showed that training and backgrounds have an impact on the nature of the fixation effect (see figure 6 below). Regarding the category "damping the shock", undergraduates in psychology provided more answers (in percentage) than designers $(p<.01)$ and entrepreneurs $(p=.07)$, whereas engineering students tended to give more answers than designers $(\mathrm{p}=.08)$. Looking at the category "protecting the egg", engineering students provided a lower percentage of answers than students in psychology $(\mathrm{p}<.05)$ and design $(\mathrm{p}=.06)$. The percentage response in the category "slowing the fall" was higher for engineers than among psychology students $(p<.01)$ and designers $(p$ $<.05)$. 
Damping the shock

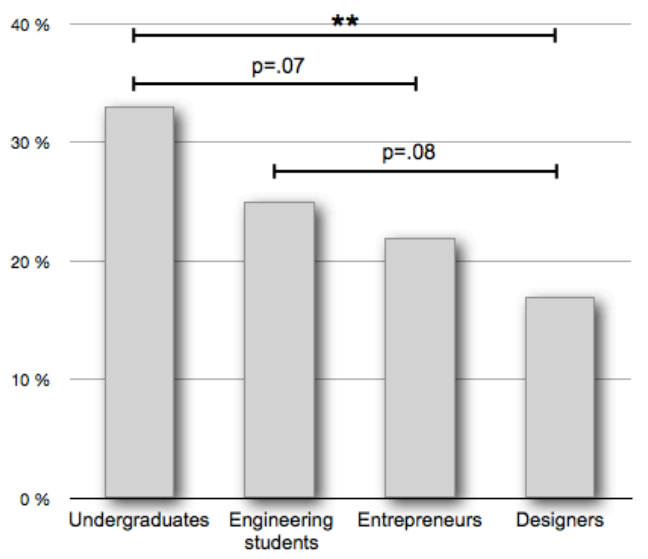

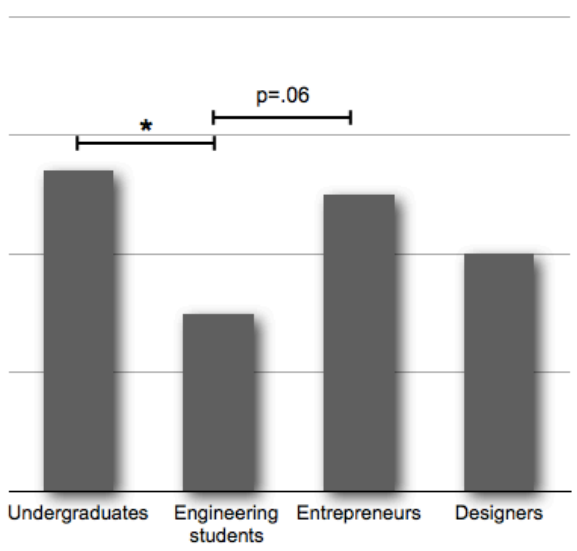

Slowing the fall

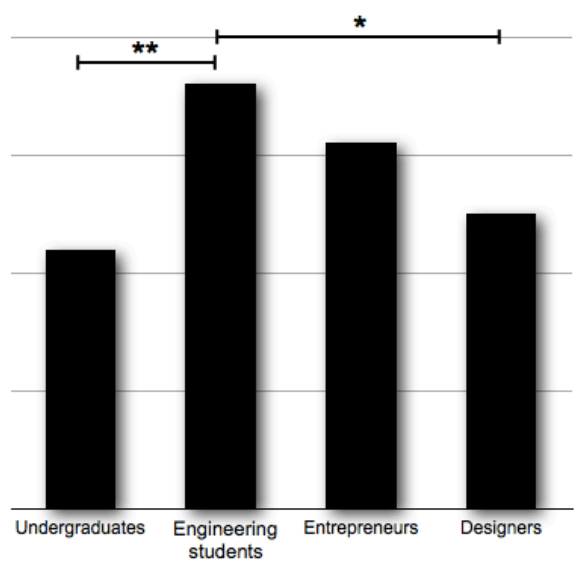

Figure 6: Evolution of the results of the percentage of answers per restrictive category based on background and training, with Fisher's exact test $(* p<.05$; $* * p<.01 ; * * * p<.005$ )

3. The expansion capabilities of designers. If we focus our analysis on the population of designers, it seemed that these individuals were better able than the other populations to generate solutions outside of the three restrictive reasoning (all $\mathrm{p}<.05$, see figure 7 below).

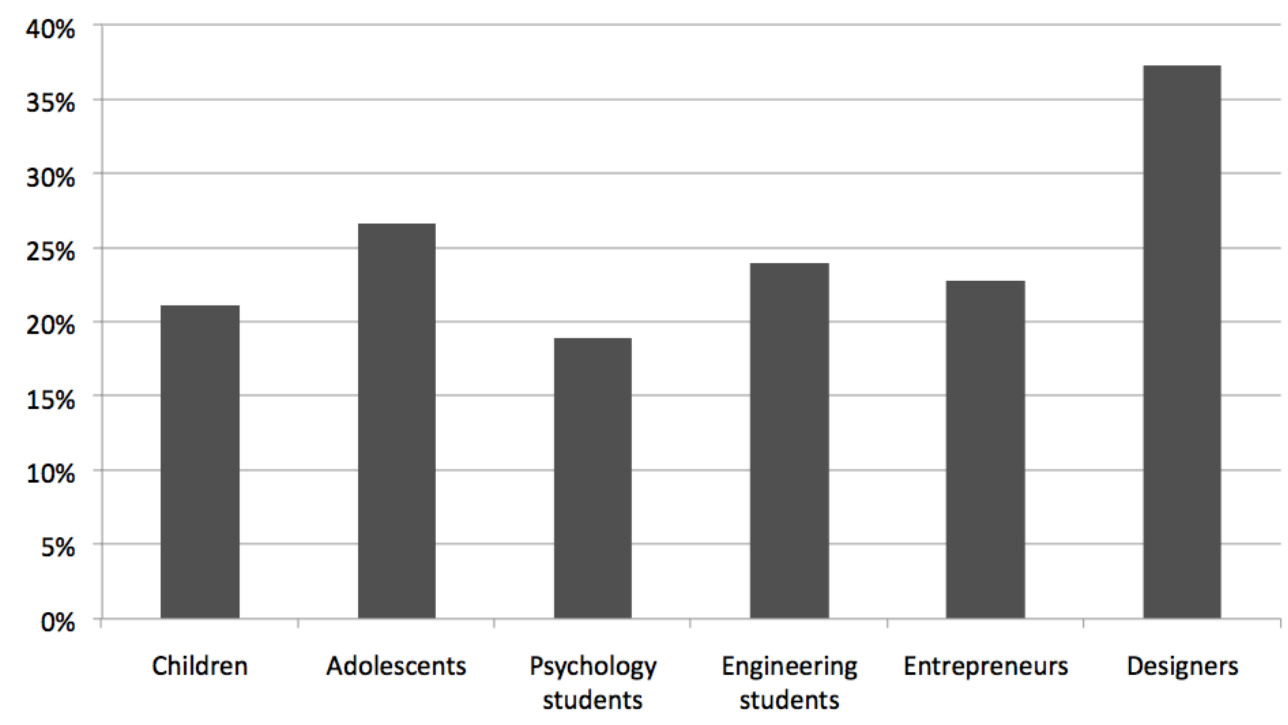

Figure 7: Expansion capabilities of different populations: \% solutions using expansive reasoning 


\section{Discussion}

In this paper, we showed how the use of design theory helps to broaden our understanding of the difficulties that occur in creative processes, namely fixation effects. We proposed to model fixation as a set of restrictive heuristics. We used a creative task to apply our theoretical framework to characterise fixation effects, and we examined this theoretical approach with a set of experiments in which participants of different ages and training were asked to generate solutions to a creative task. We then showed how different populations are fixed in different ways.

Our results showed how the nature of the fixation effect evolves with age, as adolescents provided a smaller percentage of answers regarding "protecting the egg" than adults and children. A qualitative analysis of the answers of children and adults within this heuristic showed that solutions given by children and adults were quite different, as children proposed to wrap an egg with aluminium foil, which was a solution that no adult proposed. It seems that the structure of knowledge regarding protecting an egg evolves with age, impacting the activation of the heuristic on "protecting the egg". Looking at the third category "slowing the fall", it seems that the pocket of knowledge regarding "slowing the fall" was not spontaneously activated for children and adolescents. Discussions with ten year olds confirmed that children know what parachutes are and how they work. However, this knowledge did not easily or spontaneously come to mind. Applying the model of fixation using the $\mathrm{C}-\mathrm{K}$ theory presented previously, we can make sense of this difference, as shown in figure 6 below. 


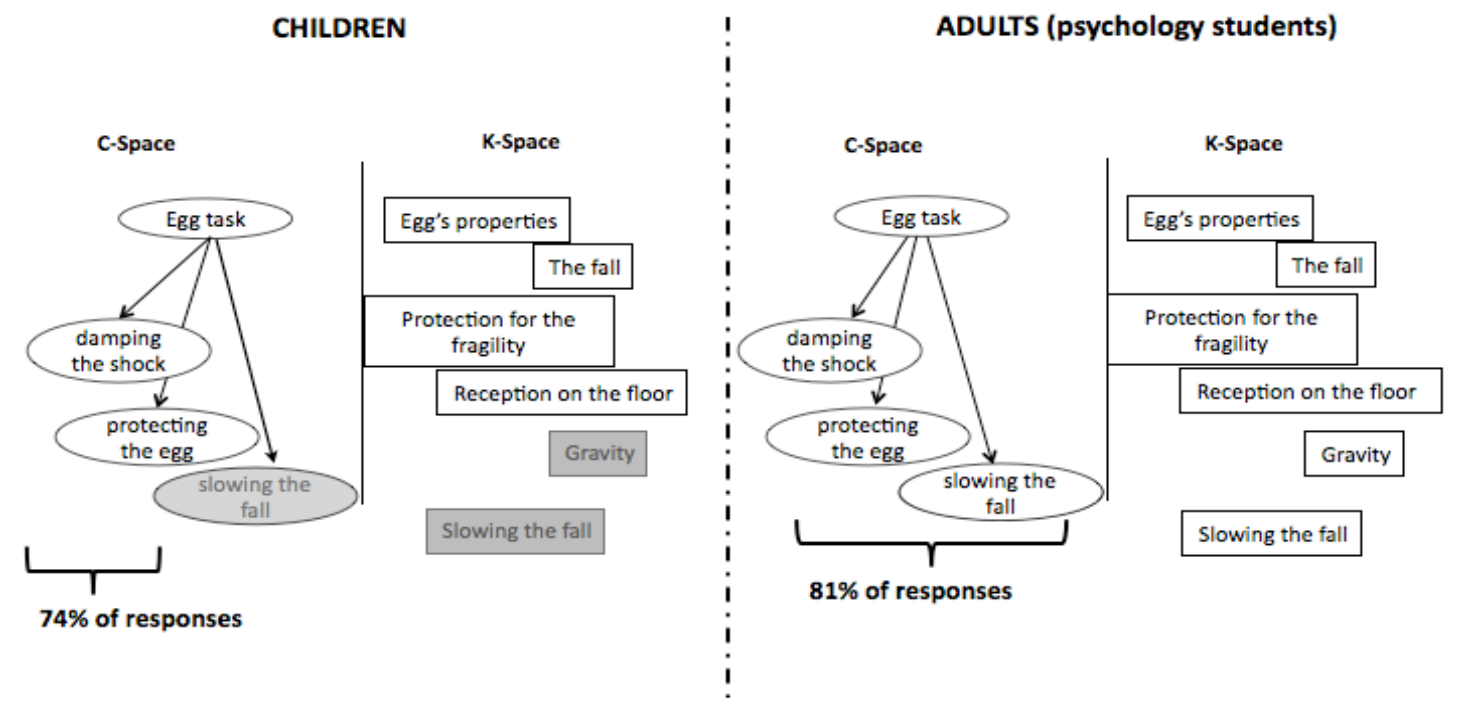

Figure 6: Modelling of the differences of fixation between children and adults using $C-K$ driven framework: a spontaneously activated knowledge base (light grey) will determine expansions in the $C$ space (in white) and lead to a reduced exploration of possible solutions (the grey concepts will not be explored)

Moreover, our study showed that engineers and entrepreneurs seem to have more scientific knowledge regarding the ways to slow the fall than psychology students or designers, which leads to a more strongly activated heuristic on slowing the fall. The percentage response in the category "slowing the fall" was higher for engineers than among psychology students and designers. A qualitative analysis of the answers given by the engineers showed that the solutions they proposed for damping the shock and protecting the egg were very detailed and complex, potentially demonstrating that their knowledge on falls made them think that no shell or mattress would work if the fall was not slower. This study on the impact of training shows that designers have developed a strong capability to resist fixation, which can be interpreted as the development of expansive heuristics, contrasting with restrictive heuristics leading to fixation. Hence, the training in design schools might push individuals to develop spontaneous generative heuristics, leading to a greater ability to expand from the fixation effect.

Our results regarding fixation through a developmental perspective and the differences due to trainings implied that the fixation mechanisms can be modelled as the development of restrictive heuristics. However, how can we then apprehend the mechanisms linked to overcoming fixation? We identified 
three capabilities that play a role in fixation and overcoming fixation, and they are as follows:

1. Restrictive heuristics development depending on the knowledge structures, leading to restrictive reasoning. This mechanism is linked to the structuring of knowledge over time through development, education and training.

2. Inhibitory capability (Houdé, 2000; Houdé \& Tzourio-Mazoyer, 2003; Houdé et al, 2000) to resist restrictive heuristics and restrictive reasoning. This mechanism reflects the ability to resist the spontaneous activation of restrictive heuristics (i.e., reasoning leading to fixation) to privilege other types of reasoning. So far, inhibition has mostly been considered as a social process constraining creativity, as it is said that in a group, social pressure and conformity can push individuals to inhibit their creativity. In agreement with the proposal of Storm and Angello (2010), we proposed that inhibitory control is a way to think of something new, and easy solutions that quickly and unconsciously come to mind have to be inhibited to make space for generative types of reasoning to develop.

3. Expansion capability to explore alternatives outside of the fixation effect using expansive reasoning. Indeed, resisting fixation is not enough to explore alternative solutions, as expansive reasoning remains to be conducted to investigate new creative possibilities. It is possible to develop expansive heuristics and to further support expansion capabilities, and it is likely that design school's curricula help to foster such generative heuristics.

We hypothesise that these three capabilities develop in parallel and at different paces. A modelling and simulation approach building on the development of these three mechanisms may provide great insights on the multi-folded nature of fixation in creative design. Further research should investigate this matter. Moreover, theoretical and experimental work on fixation in groups would greatly enrich the perspectives exposed in this paper. 


\section{References}

Abraham, A., and Windmann, S. (2007). Creative cognition: The diverse operations and the prospect of applying a cognitive neuroscience perspective, Methods, 42, 38-48.

Adamson, R.E. (1952). Functional fixedness as related to problem solving: A repetition of three experiments. Journal of Experimental Psychology, 44, 288291.

Agogué, M., Kazakçi, A., Weil, B., and Cassotti, M. (2011) The Impact of Examples on Creative Design: Explaining Fixation and Stimulation Effects. International Conference on Engineering Design, ICED'11, Technical University of Denmark

Agogué, M., Le Masson, P., and Robinson, D. K. R. (2012). Orphan innovation, or when path-creation goes stale": a design framework to characterize path-dependence in real time. Techonology Analysis and Strategy Management, 24(6), 603-616.

Allen, A.P., and Thomas, K.E. (2011). A Dual Process Account of Creative Thinking, Creativity Research Journal, 23(2), 109-118.

Arthur, W. B. (1989). Competing technologies, increasing returns, and lock-in by historical events. The Economic Journal, 99, 116-131.

Bonnardel, N., and Marmèche, E. (2004). Expert designers: Towards stimulating analogical thinking. Creativity and Innovation Management, 13(3), 176-186.

Bonnardel, N., and Zenasni, F. (2007). The impact of technology on creativity in design: An enhancement? Creativity and Innovation Management, 19(2), 180191.

Cardoso, C., Badke-Schaub, P., and Luz, A., (2009), Design Fixation on NonVerbal Stimuli: The Influence of Simple Vs Rich Pictorial Information on Design Problem Solving, International Design Engineering Technical Conferences, San Diego, CA.

David, P.A. (1985). Clio and the economics of QWERTY. The American Economic Review, 75(2), 332-337. 
Defeyter, M.A. and German, T.P. (2003). Acquiring an understanding of design: Evidence from children's insight problem solving. Cognition, 89, 133155.

Dodds, R. A., Smith, S. M., \& Ward, T. B. (2002). The use of environmental clues during incubation. Creativity Research Journal, 14, 287-304.

Dong, A., \& Sarkar, S. (2011). Unfixing design fixation: From cause to computer simulation. The Journal of Creative Behavior, 45, 147-159.

Duncker K. (1945). On problem-solving. Psychological Monographs, 58(5, Whole No. 270).

Hatchuel, A. et Weil, B. (2003). A new approach of innovative design: an introduction to $\mathrm{CK}$ theory, XIVth International Conference on Engineering Design, Stockholm, Sweden, 19th-21st August.

Hatchuel, A. et Weil, B. (2007). Design as forcing : Deepening the foundations of C-K theory. XVIth International Conference on Engineering Design, Paris, 28th-31th August.

Hatchuel, A., Le Masson, P., and Weil, B. (2011). Teaching Innovative Design Reasoning: How C-K Theory Can Help to Overcome Fixation Effect. Artificial Intelligence for Engineering Design, Analysis and Manufacturing, 25(1), 77-92.

Hatchuel, A., and Weil, B. (2009). C-K design theory: an advanced formulation. Research in Engineering Design, 19(4), 181-192.

Jansson, D.G., and Smith, S.M. (1991). Design fixation, Design Studies, 12 (1), 3-11.

Houdé, O. (2000). Inhibition and cognitive development: Object, number, categorization, and reasoning. Cognitive Development, 15, 63-73.

Houdé, O., \& Tzourio-Mazoyer, N. (2003). Neural foundations of logical and mathematical cognition. Nature Reviews Neuroscience, 4(6), 507-514.

Houdé, O., Zago, L., Mellet, E., Moutier, S., Pineau, A., Mazoyer, B., et al. (2000). Shifting from the perceptual brain to the logical brain: The neural impact of cognitive inhibition training. Journal of Cognitive Neuroscience, 12, 721728.

Kahneman, D., and Frederick, S. (2007). Frames and brains: Elicitation and control of response tendencies. Trends in Cognitive Sciences, 11(2), 45-46.

Kaplan, S., and Tripsas, M. (2008). Thinking about technology: Applying a cognitive lens to technical change. Research Policy, 37(5), 790-805. 
Kohn, N. and S. Smith (2011), Collaborative Fixation: Effects of Others' Ideas on Brainstorming, Applied Cognitive Psychology, 25(3), 359-371.

Le Masson, P., Weil, B., \& Hatchuel, A. (2010). Strategic Management of Design and Innovation. Cambridge: Cambridge University Press.

Linsey, J., Tseng, I., Fu, K., Cagan, J., and Wood, K., (2009), "Reducing and Perceiving Design Fixation: initial results from an NSF-sponsored workshop," International Conference on Engineering Design, Stanford, CA.

Meyer, U., and Schubert, C. (2007). Integrating path dependency and path creation in a general understanding of path constitution. The role of agency and institutions in the stabilisation of technological innovations. Science, Technology \& Innovation Studies, 3(1), 23-44.

Perttula, M K and Liikkanen, L A (2006) Exposure effects in design idea generation: unconscious conformity or a product of sampling probability? in $\mathrm{M}$ Jonsson and R Unnporsson (eds) Proceedings of NordDesign 2006, Reykjavik, Iceland

Prahalad. C. K. and R. Bettis (1986), "The Dominant Logic: A New Linkage Between Diversity and Performance," Strategic Management Journal, 7 (6), $485-50$

Purcell, T. and Gero, J. S. (1996). Design and other types of fixation. Design Studies, 17(4), 363-383.

Smith, S.M., Linsey, J. and Kerne, A. (2010) Using evolved analogies to overcome creative design fixation, 1st International Conference on Design Creativity, 29th November - 1st December, Kobe, Japan.

Smith, S.M., Ward, T.B., and Finke, R.A. (1995). The creative cognition approach. Cambridge, MA, US: The MIT Press.

Storm, B. C., \& Angello, G. (2010). Overcoming fixation: Creative prob- lem solving and retrieval-induced forgetting. Psychological Science, 21, 1263-1265.

Thrane, S., Blaabjerg, S., and Møller, R. H. (2010). Innovative path dependence: Making sense of product and service innovation in path dependent innovation processes. Research Policy, 39(7), 932-944.

Tseng, I., Moss, J., Cagan, J., and Kotovsky, K., (2008) The Role of Timing and Analogical Similarity in the Stimulation of Idea Generation in Design, Design Studies, 203-221.

Viswanathan, V.K. and Linsey, J.S., (2011) Design Fixation in Physical Modeling: An Investigation on the Role of Sunk Cost. International Design 
Engineering Technical Conferences \& Computers and Information in Engineering Conference, Washington, DC, 2011.

Wiley, J. (1998). Expertise as mental set: The effects of domain knowledge in creative problem solving. Memory and Cognition, 26, 716-730.

Youmans, R. J. (2010). The effects of physical prototyping and group work on the reduction of design fixation. Design Studies, 32, 115-138.

Youmans, R. J. (2011). Design fixation in the wild: Design environments and their influence on fixation. The Journal of Creative Behavior, 45, 101-107. 